\title{
Application of Graphene Silicone Grease in heat dissipation for the Intel Core i5 Processor
}

\author{
Mai Thi Phuong"**, Bui Anh Tuan\#, Trần Văn Hậu\#*, Pham Van Trinh", Nguyen Nang Dinh*, \\ Phan Ngoc Minh ${ }^{* *}$, Bui Hung Thang ${ }^{\#}$ \\ \# Institute of Materials Science, Vietnam Academy of Science and Technology, Hanoi, Vietnam \\ ${ }^{*}$ VNU University of Engineering and Technology, Ha Noi, Vietnam \\ ** Graduate University of Science and Technology, Vietnam Academy of Science and Technology, Hanoi, Vietnam \\ E-mail: thangbh@ims.vast.ac.vn
}

\begin{abstract}
Graphene was known as the material that owning many superiority properties and high thermal conductivity. Thermal conductivity of single-layer graphene was up to $5200 \mathrm{~W} / \mathrm{mK}$ (compared to the thermal conductivity of Carbon nanotubes $2000 \mathrm{~W} / \mathrm{mK}$ and Silver $410 \mathrm{~W} / \mathrm{mK}$ ). This had suggested that graphene is the most potential material for heat dissipation applications for electronic devices, such as a computer microprocessor, high power LED... To enhance the dispersion of the GNPs silicone matrix, we were functionalized graphene nanoplatelets (GNPs) with carboxyl (-COOH) groups. The silicone thermal greases containing GNPs were prepared by High- Energy Ball Milling method (8000D Mixer /Mill). The results of SEM, FTIR, Raman showed the presence of the carboxyl groups in GNPs and GNPs uniform dispersion dispersed in grease. The results of thermal conductivity from Transient Hot Bridge THB-100 showed that thermal conductivity enhancement was up to $234 \%$ with Gr-COOH 1.0 vol. $\%$. Thermal grease is used as a thermal interface material to coolants for Intel Core i5 processor. The results of thermal dissipation efficiency shown the saturation temperature of the processor using thermal grease containing 1.0 vol. $\% \mathrm{Gr}-\mathrm{COOH}$ decreased $4^{\circ} \mathrm{C}$, compared to the silicone grease.
\end{abstract}

Keywords - thermal grease, silicone grease, graphene, CPU, Intel Core i5 processor.

\section{INTRODUCTION}

Nowadays, the process of miniaturization with the development of high-power electronic devices and manufacturing processes developed at the nanometer-level. The electronic devices allow higher transistor integration density in the processor (CPU) [1-4]. However, computer processors action for a long will consume energy and release large amounts of heat. The excessive amount of heat generated will reduce the lifespan, reliability and efficiency of the CPU because the electronic devices only work into a certain temperature limit [5]. Therefore, the heat generated from high-power electronic devices should be dissipated as quickly and effectively as possible, to maintain the operating temperatures of the devices at the desired level. In the way stated, the heat dissipation enhancement has become one of the most crucial issues that raise the reliability, boosts performance and stability of high-power electronic devices such as microprocessors, and especially is Central Processing Unit (CPU) [6,7].

Current cooling methods are only reaching a certain limit due to the interface area between CPU and heatsink $[8,9]$.
Therefore, the use of thermal grease in high-power electronic devices of great interest by researchers and manufacturers. Thermal grease is a typical thermal interface material (TIM) [10], usually used to increase the thermal conductivity between microprocessors and heat sinks [11]. The main materials of thermal grease consist of the matrix polymer and filler [12,13]. The filler materials are key thermal conductivity ingredient in silicone thermal grease. It is sized particles $\mu \mathrm{m}$ with high thermal conductivity and dispersed in the base silicone, often use inorganic or metal nanomaterials with high thermal conductivity [14-18].

Thermal silicon grease fills the gaps between two solid surfaces and establishes an efficient heat path, thereby enhancing thermal conductivity [19-21]. The thermal conductivity of fat increases with increasing filler content. However, many factors have an effect on thermal conductivity of grease, such as the size of particles, the particle dispersion in base grease, and the thermal properties of the dispersed particle $[22,23]$. In recent years, many thermal greases have been reported using nanomaterials with high conductivity for better performance. Researchers have recently shown much interest in the issue of finding new 
materials for thermal grease in the heat dissipation future issue[24,25].

Recently, Graphene is a two-dimensional nanocarbon material with the hexagonally packed structure compromised of sp2-hybridized carbon atoms, discovered by Andre Geim and Kostya Novoselov in 2004 [26]. Baladin et al.'s research showed that the in-plane thermal conductivity of single-layer graphene was up to $5200 \mathrm{~W} / \mathrm{mK}$ [27] (compared to the thermal conductivity of CNTs $2000 \mathrm{~W} / \mathrm{mK}$ and Ag 410 $\mathrm{W} / \mathrm{mK}$ ) [28]. This suggests an approach in applying graphene in grease or liquid for thermal dissipation systems for computer processors and other high-power electronic devices.

In this paper, we report on the new results in the fabrication of high thermal conductivity silicone grease containing graphene, and application grease for enhancing heat dissipation of Intel Core i5 processor [29].

\section{THE MATERIAL AND METHOD}

The graphene nanoplatelets materials (GNPs) were purchased from ACS Material Company with a purity of $99.5 \%$, thickness $20 \mathrm{~nm}$, diameter 5-10 $\mu \mathrm{m}$, density 2,3 $\mathrm{g} / \mathrm{cm}^{3}$, and specific surface area $20-40 \mathrm{~m}^{2} / \mathrm{g}$. GNPs was functionalized by treatment with a mixture $\mathrm{HNO} 3$ and $\mathrm{H} 2 \mathrm{SO} 4$ acids at a ratio of $1: 3(\mathrm{v} / \mathrm{v})$ at a temperature of $70^{\circ} \mathrm{C}$ for $5 \mathrm{~h}$ to form a carboxyl (-COOH) group, as schematically shown in Figure 1. Raman spectroscopy was used to analyze graphitic change the graphene materials after acid treatment. Chemical bonds and elements in thermal grease were characterized by Fourier-transform infrared spectroscopy (FTIR).

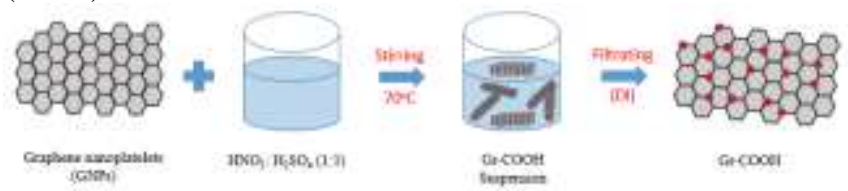

Fig.1. The creative process of graphene functionalized by carboxyl ($\mathrm{COOH})$ group

In order to disperse the $\mathrm{Gr}-\mathrm{COOH}$ in the silicone grease, we using by $8000 \mathrm{D}$ Mixer /Mill (High- Energy Ball Mill) at a speed of $8000 \mathrm{rpm}$ for 3 hours. Field-emission scanning electron microscope (FESEM) was used to examine the size, morphology, and distribution of $\mathrm{Gr}-\mathrm{COOH}$ in the thermal grease. Thermal conductivity of the grease is measured by Transient Hot Bridge THB-100 (Linseis, Germany) at room temperature. Figure 2 is a schematic view of the thermal dissipation system for a computer processor using silicone grease containing Gr-COOH. In this model, thermal grease was painted on the interface between the CPU chip and the heatsink. We use the air conditioner to keep the ambient temperature at $28{ }^{\circ} \mathrm{C}$ for all measurements. Thermal grease replaces the air gap with thermal conductivity of 0.026 $\mathrm{W} / \mathrm{m} . \mathrm{K}$ and fills the gap between the rugged surface and the heat path setting, thereby increasing the heat transfer efficiency. The thermal dissipation efficiency was evaluated by using dedicated software and built-in temperature sensors inside the microprocessor to measure the temperature of the microprocessor directly.

The computer used in this study has the following configuration: Intel Core i5 - $3570 \mathrm{~K}$ Processor, Corsair's 4
GB DDR3 SODIMM Memory, Toshiba's 1 TB Hard Disk Drive, Asrock H61M-VS3 Mainboard, and Window 10 Ultimate Service Pack 1 Operating System for all experiments. The temperature of the microprocessor was measured by using the Core Temp 1.10.2- 64 bit software. The microprocessor was pushed to the maximum $(100 \%$ usage of the processor) by using Prime95 32 bit 29.3 build 1 software.

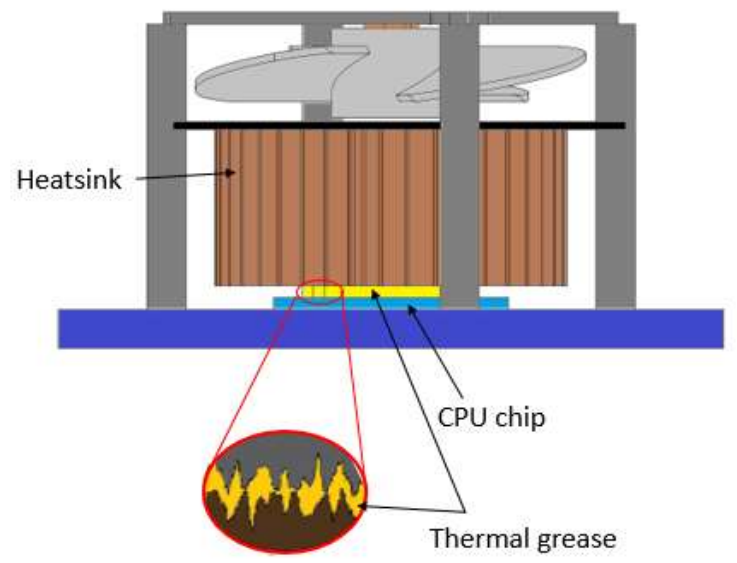

Fig.2. Scheme of the cooling system using thermal grease containing Gr$\mathrm{COOH}$

\section{RESULTS AND DISCUSSION}

Figure 3 shows a typical FESEM image of the GNPs hight magnification. The thickness of nanosheets in the range of 2-10 nm, the average diameter was about 5-10 $\mu \mathrm{m}$ with high cleanliness and purity $99 \%$.

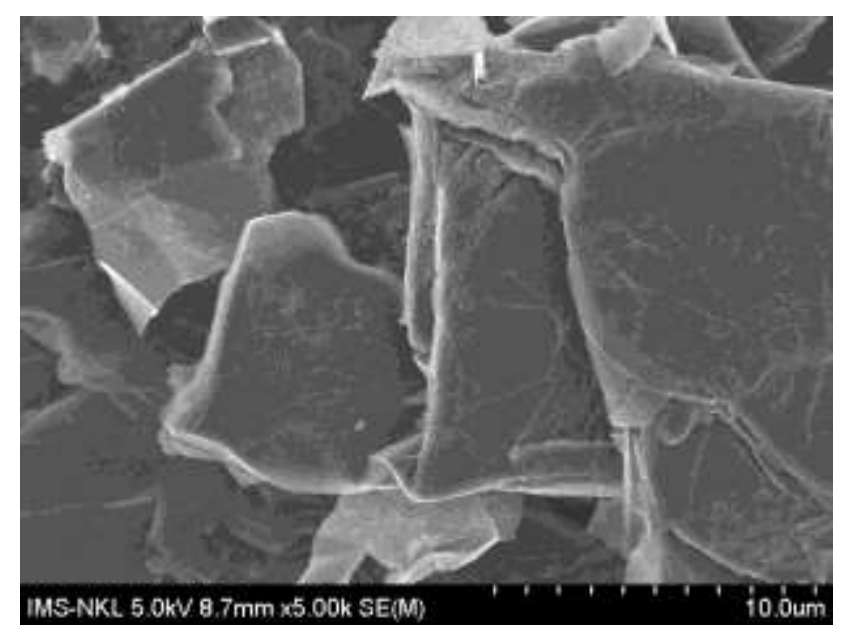

Fig.3. FESEM image of graphene nanoplatelets

Raman scattering is a technique to examine the changes in the surfaces and the structures of GNPs. Figure 4 clearly shows that the $G$ band (around 1582.87) and 2D band (around 2678.2). The D-band intensity was appeared in the functionalized GNPs compared to the pristine GNPs. The intensity ratio of $\mathrm{D}$ lines to $\mathrm{G}$ lines was different, suggesting some changes in the surfaces and the structures of the GNPs. This result indicates that some of the $\mathrm{sp}^{2}$ carbon atoms $(\mathrm{C}=\mathrm{C})$ were converted to $\mathrm{sp}^{3}$ carbon atoms $(\mathrm{C}-\mathrm{C})$ at the surfaces of the MWCNTs after the acid treatment in $\mathrm{HNO}_{3} / \mathrm{H}_{2} \mathrm{SO}_{4}$. 


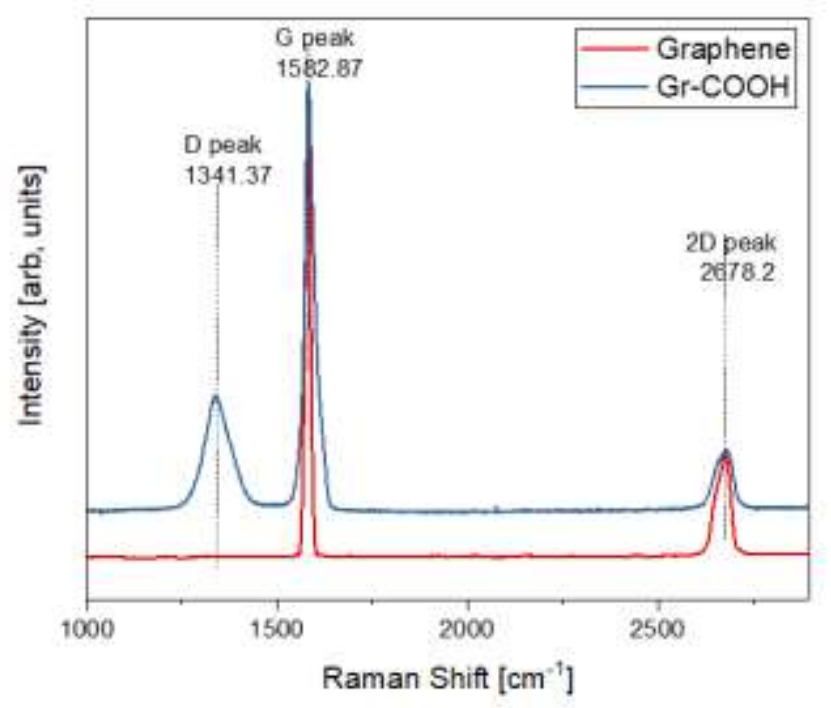

Fig.4. Raman spectra of Graphene (red line), Gr-COOH (blue line)

Figure 5 presents the typical FTIR spectra of the pristine GNPs and Gr-COOH. Some important peaks are seen after the GNPs have been treated with a mixture of $\mathrm{H}_{2} \mathrm{SO}_{4}$ and $\mathrm{HNO}_{3}$. The vibration of $\mathrm{O}-\mathrm{H}$ bonding in the carboxyl group is shown as a peak at $3446 \mathrm{~cm}^{-1}$. It was expanded more than that of the $\mathrm{O}-\mathrm{H}$ bonding of $\mathrm{H}_{2} \mathrm{O}$. The peak at $1708 \mathrm{~cm}^{-1}$ showed the existence of vibrations of the $\mathrm{C}=\mathrm{O}$ bond in the carboxyl group. This shows the importance of proving the existence of carboxyl $(\mathrm{COOH})$ functional groups due to the oxidation resulting from the nitric and the sulfuric acids. This clearly shows that the acids functionalized the surfaces of the GNPs.

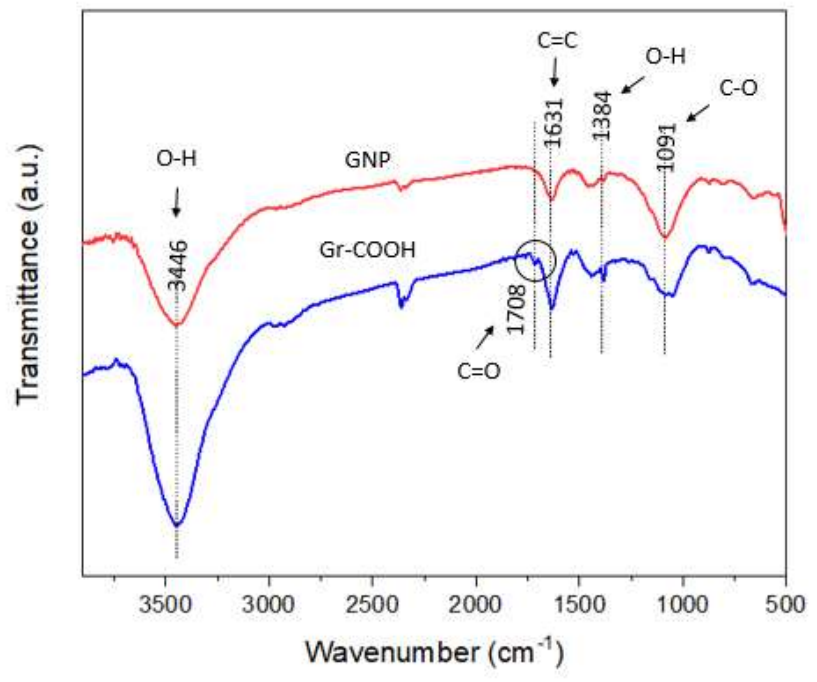

Fig.5. FTIR transmission spectra of pristine GNPs, Gr-COOH.

Fig. 6a shows the SEM images of silicone thermal grease. As can be seen, the silicone thermal grease used in this research contains some large and small filling particles inequitably distributed in the grease. Fig. $6 \mathrm{~b}$ shows the SEM images of thermal grease containing 1.0 vol. $\%$ Gr-COOH as prepared. This result shows the distribution of the metal oxide particles of the grease and $\mathrm{Gr}-\mathrm{COOH}$ inside thermal grease after annealing. This indicates that silicone grease clings to graphene. In other words, Gr-COOH were good compatibility and well-dispersed in the silicone grease, thereby enhancing the thermal conductivity of grease.
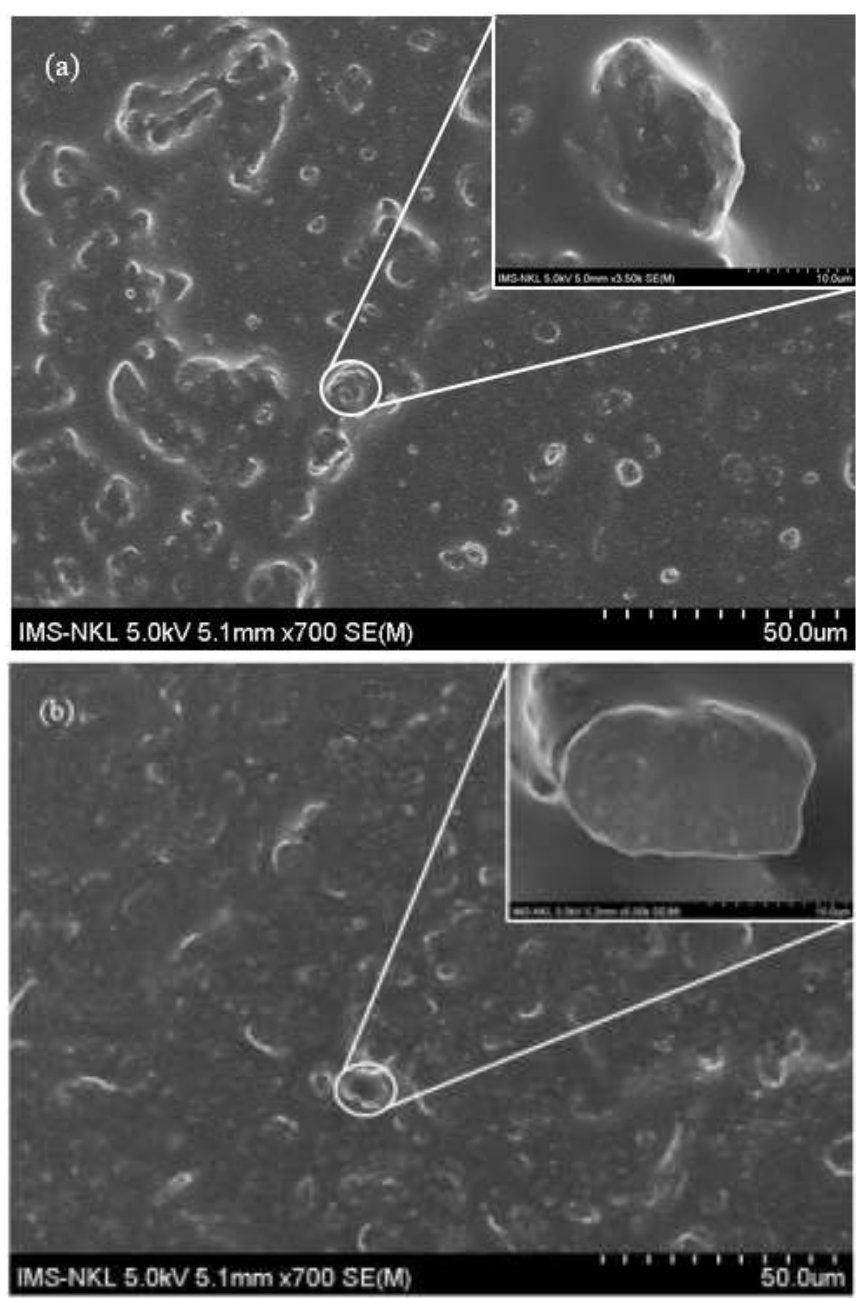

Fig.6. FESEM image of silicone thermal grease (a) and silicone thermal grease containing $\mathrm{Gr}-\mathrm{COOH}(\mathrm{b})$

TABLE 1

THE RESULT THERMAL CONDUCTVITY OF THE GREASE

\begin{tabular}{|l|l|l|l|l|}
\hline \multirow{2}{*}{} & \multicolumn{4}{|l|}{ Thermal conductivity of grease containing GNP } \\
\cline { 2 - 5 } & $\begin{array}{l}\mathbf{0 . 2 5} \\
\text { vol.\% }\end{array}$ & $\begin{array}{l}\mathbf{0 . 5} \\
\text { vol.\% }\end{array}$ & $\mathbf{0 . 7 5}$ vol.\% & $\mathbf{1 . 0}$ vol.\% \\
\hline \multirow{2}{*}{$\mathrm{k}$} & 3.210 & 4.281 & 5.012 & 6.172 \\
& W/m.K & W/m.K & W/m.K & W/m.K \\
\hline \multirow{2}{*}{$\mathrm{k}-\mathrm{k}_{0}$} & 1.276 & 2.437 & 3.168 & 4.328 \\
& W/m.K & W/m.K & W/m.K & W/m.K \\
\hline \multirow{2}{*}{$\left(\mathrm{k}-\mathrm{k}_{0}\right) / \mathrm{k}_{0}$} & $74 \%$ & $130 \%$ & $171 \%$ & $234 \%$ \\
\hline
\end{tabular}

The statistic results of thermal conductivity and the thermal conductivity enhancement of thermal grease with different $\mathrm{Gr}-\mathrm{COOH}$ concentration are reported in table 1. In which, $\mathrm{k}$ and $\mathrm{k}_{0}$ are the thermal conductivity of the silicone thermal grease and the thermal grease containing $\mathrm{Gr}-\mathrm{COOH}$, respectively. The equations $\left(\mathrm{k}-\mathrm{k}_{0}\right) / \mathrm{k}_{0}$ shown the thermal conductivity enhancement. The result shows with $0.25,0.5$, 0.75 and 1 vol.\% Gr-COOH the thermal conductivity of thermal grease containing $\mathrm{Gr}-\mathrm{COOH}$ was measured to be $3.210,4.281,5.012,6.172 \mathrm{~W} / \mathrm{m} . \mathrm{K}$. Similarly, the thermal conductivity enhancement was calculated to be $74 \%, 130 \%$, 
$171 \%, 234 \%$ corresponding to the thermal grease containing $0.25,0.5,0.75$ and 1.0 vol. $\%$, respectively. Results showed that $\mathrm{Gr}-\mathrm{COOH} 1.0$ vol. $\%$ had the highest thermal conductivity enhancement of $234 \%$ compared with silicone grease.

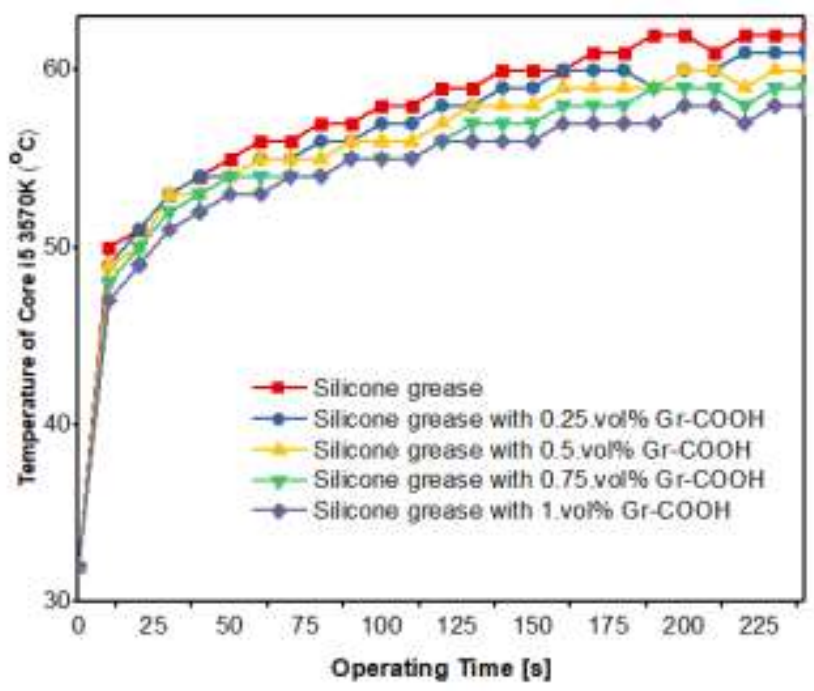

Fig.7. The measured temperature of the microprocessor as a function of the operation time in the case of using thermal grease

The temperature microprocessor of the can be measured directly when it during the operation of the computer at full load mode. We use an air conditioner to kept well room temperature at $28^{\circ} \mathrm{C}$ for all measurements. We use thermal grease to reduce the saturation temperature and slow down the temperature increase of the processor. Figure 7 shows the microprocessor's experimental temperature as a function of working time when using thermal grease. At the initial time, the temperature of the microprocessor was about $32^{\circ} \mathrm{C}$, after about 240 seconds the temperature reached saturation. The saturation temperature of the microprocessor reached $62^{\circ} \mathrm{C}$ when using silicone thermal grease and it reached $61{ }^{\circ} \mathrm{C}$, $60^{\circ} \mathrm{C}, 59^{\circ} \mathrm{C}, 58^{\circ} \mathrm{C}$ with silicone thermal grease containing $\mathrm{Gr}-\mathrm{COOH}$ with 0.25 vol. $\%, 0.5$ vol. $\%, 0.75 \%$ vol. $\%, 1$ vol. $\%$, respectively. Similarly, the saturation temperature decrease of CPU was calculated to be 1, 2, 3, 4 correspondings to the thermal grease containing $0.25,0.5$, 0.75 and 1.0 vol. $\%$, responding. The lowest saturation temperature of $\mathrm{CPU}$ was $58^{\circ} \mathrm{C}$ with grease containing 1 vol. $\% \mathrm{Gr}-\mathrm{COOH}$.

\section{IV.CONCLUSION}

The successful functionalization $\mathrm{Gr}-\mathrm{COOH}$ by a mixture of the acid solution was proven by Raman and FTIR spectral measurements. The SEM images proved that graphene nanoplatelets dispersed in the based grease by high energy ball mill method. The results thermal conductivity from Transient Hot Bridge THB-100 showed that thermal conductivity enhancement was up to $234 \%$ with $\mathrm{Gr}-\mathrm{COOH}$ 1.0 vol.\%. The thermal dissipation efficiency of the PC's microprocessor examined and evaluated. Compared to the silicone grease, the saturation temperature of the processor using thermal grease containing 1.0 vol.\% $\mathrm{Gr}-\mathrm{COOH}$ decreased $4{ }^{\circ} \mathrm{C}$. The obtained results confirmed the advantages of using $\mathrm{Gr}-\mathrm{COOH}$ for thermal grease in microprocessors and other high-power electronic devices.

\section{ACKNOWLEDGMENT}

This study was funded from: "For Inspiration and Recognition of Science and Technology (FIRST) under grant No.16/FIRST/1.a/IMS".

\section{REFERENCES}

[1] [1] P. K. Schelling, L. Shi, and K. E. Goodson, "Managing heat for electronics," Mater. Today, vol. 8, no. 6, pp. 30-35, Jun. 2005.

[2] [2] K. M. Razeeb, E. Dalton, G. L. W. Cross, and A. J. Robinson, "Present and future thermal interface materials for electronic devices," Int. Mater. Rev., vol. 63, no. 1, pp. 1-21, Jan. 2018.

[3] [3] N. T. Hong, K. H. Koh, N. T. T. Tam, P. N. Minh, P. H. Khoi, and S. Lee, "Combined model for growing mechanism of carbon nanotubes using HFCVD: effect of temperature and molecule gas diffusion," Thin Solid Films, vol. 517, no. 12, pp. 3562-3565, Apr. 2009.

[4] [4] B. Hung Thang, P. Van Trinh, N. Van Chuc, P. H. Khoi, and P. N. Minh, "Heat Dissipation for Microprocessor Using Multiwalled Carbon Nanotubes Based Liquid," Sci. World J., vol. 2013, pp. 1-6, 2013.

[5] [5] J. Falck, C. Felgemacher, A. Rojko, M. Liserre, and P. Zacharias, "Reliability of Power Electronic Systems: An Industry Perspective," IEEE Ind. Electron. Mag., vol. 12, no. 2, pp. 24-35, Jun. 2018.

[6] [6] Y. Song and B. Wang, "Survey on Reliability of Power Electronic Systems," IEEE Trans. Power Electron., vol. 28, no. 1, pp. 591-604, Jan. 2013.

[7] [7] F. L. Tan and C. P. Tso, "Cooling of mobile electronic devices using phase change materials," Appl. Therm. Eng., vol. 24, no. 2-3, pp. 159-169, Feb. 2004.

[8] [8] R. L. Webb and J. P. Gwinn, "Low melting point thermal interface material," in ITherm 2002. Eighth Intersociety Conference on Thermal and Thermomechanical Phenomena in Electronic Systems (Cat. No.02CH37258), pp. 671-676.

[9] [9] D. D. L. Chung, "Thermal Interface Materials," J. Mater. Eng. Perform., vol. 10, no. 1, pp. 56-59, Feb. 2001.

[10] [10]F. Sarvar, D. Whalley, and P. Conway, "Thermal Interface Materials - A Review of the State of the Art," in 2006 1st Electronic Systemintegration Technology Conference, 2006, pp. 1292-1302.

[11] [11]J. Due and A. J. Robinson, "Reliability of thermal interface materials: A review," Appl. Therm. Eng., vol. 50, no. 1, pp. 455-463, Jan. 2013.

[12] [12] S. Yeol Jeong and Y. Suk Choi, "Measurement of interfacial thermal resistance of silicone based grease in wide temperature range by laser flash method," High Temp. Press., vol. 48, no. 1-2, p. 59, 2019.

[13] [13] M. A. Vadivelu, C. R. Kumar, and G. M. Joshi, "Polymer composites for thermal management: a review," Compos. Interfaces, vol. 23, no. 9, pp. 847-872, Nov. 2016.

[14] [14] D. D. . Chung, "Materials for thermal conduction," Appl. Therm. Eng., vol. 21, no. 16, pp. 1593-1605, Nov. 2001

[15] [15]H. Chen, H. Wei, M. Chen, F. Meng, H. Li, and Q. Li, "Enhancing the effectiveness of silicone thermal grease by the addition of functionalized carbon nanotubes," Appl. Surf. Sci., vol. 283, pp. 525-531, Oct. 2013.

[16] [16] W. Zhou, S. Qi, C. Tu, H. Zhao, C. Wang, and J. Kou, "Effect of the particle size of $\mathrm{Al} 2 \mathrm{O} 3$ on the properties of filled heat-conductive silicone rubber," J. Appl. Polym. Sci., vol. 104, no. 2, pp. 1312-1318, Apr. 2007.

[17] [17] Q. Wang, W. Gao, and Z. Xie, "Highly thermally conductive room-temperature-vulcanized silicone rubber and silicone grease," J. Appl. Polym. Sci., vol. 89, no. 9, pp. 2397-2399, Aug. 2003.

[18] [18] W. Yu, H. Xie, L. Yin, J. Zhao, L. Xia, and L. Chen, "Exceptionally high thermal conductivity of thermal grease: Synergistic effects of graphene and alumina," Int. J. Therm. Sci., vol. 91, pp. 76-82, May 2015.

[19] [19]J. Hansson, T. M. J. Nilsson, L. Ye, and J. Liu, "Novel nanostructured thermal interface materials: a review," Int. Mater. Rev., vol. 63, no. 1, pp. 22-45, Jan. 2018.

[20] [20]U. Eduok, O. Faye, and J. Szpunar, "Recent developments and applications of protective silicone coatings: A review of PDMS 
functional materials," Prog. Org. Coatings, vol. 111, pp. 124-163, Oct. 2017.

[21] [21]L. Calabrese, L. Bonaccorsi, A. Freni, and E. Proverbio, "Silicone composite foams for adsorption heat pump applications," Sustain. Mater. Technol., vol. 12, pp. 27-34, Jul. 2017.

[22] [22] N. Burger, A. Laachachi, M. Ferriol, M. Lutz, V. Toniazzo, and D. Ruch, "Review of thermal conductivity in composites: Mechanisms, parameters and theory," Prog. Polym. Sci., vol. 61, pp. 1-28, Oct. 2016.

[23] [23] S. Zhai, P. Zhang, Y. Xian, J. Zeng, and B. Shi, "Effective thermal conductivity of polymer composites: Theoretical models and simulation models,” Int. J. Heat Mass Transf., vol. 117, pp. 358-374, Feb. 2018.

[24] [24]P. Zhang, J. Zeng, S. Zhai, Y. Xian, D. Yang, and Q. Li, "Thermal Properties of Graphene Filled Polymer Composite Thermal Interface Materials," Macromol. Mater. Eng., vol. 302, no. 9, p. 1700068 , Sep. 2017.
[25] [25]H. Chen et al., "Thermal conductivity of polymer-based composites: Fundamentals and applications,” Prog. Polym. Sci., vol. 59, pp. 41-85, Aug. 2016.

[26] [26]K. S. Novoselov, "Electric Field Effect in Atomically Thin Carbon Films," Science (80-. )., vol. 306, no. 5696, pp. 666-669, Oct. 2004.

[27] [27] A. A. Balandin et al., "Superior Thermal Conductivity of SingleLayer Graphene," Nano Lett., vol. 8, no. 3, pp. 902-907, Mar. 2008.

[28] [28]H. T. Bui, V. C. Nguyen, V. T. Pham, T. T. T. Ngo, and N. M. Phan, "Thermal dissipation media for high power electronic devices using a carbon nanotube-based composite," Adv. Nat. Sci. Nanosci. Nanotechnol., vol. 2, no. 2, p. 025002, Apr. 2011.

[29] [29] B. H. Thang, P. Van Trinh, L. D. Quang, N. T. Huong, P. H Khoi, and P. N. Minh, "Heat dissipation for the Intel Core i5 processor using multiwalled carbon-nanotube-based ethylene glycol,” J. Korean Phys. Soc., vol. 65, no. 3, pp. 312-316, 2014. 